\title{
Recent Research in Science Teaching and Learning
}

\section{Sarah L. Eddy*}

Department of Biological Sciences, STEM Transformation Institute, Florida International University, Miami, FL 33199

\begin{abstract}
The Current Insights feature is designed to introduce life science educators and researchers to current articles of interest in other social science and education journals. In this installment, I highlight three diverse research studies: one addresses the relationships between active learning and teaching evaluations; one presents an observation tool for documenting metacognition in the classroom; and the last explores things teachers can say to encourage students to employ scientific reasoning during class discussions.
\end{abstract}

\section{STUDENT EVALUATIONS AND ACTIVE LEARNING}

Henderson, C., Khan, R., \& Dancy, M. (2018). Will my student evaluations decrease if I adopt an active learning instructional strategy? American Journal of Physics, 86(12), 934-942. https://doi.org/10.1119/1.5065907

Student evaluations are widely used and are often the sole source for the evaluation of faculty teaching. As described in the Introduction, fear that one's student evaluations may decrease is one of the oft-cited reasons for faculty not adopting active-learning techniques. Yet this phenomenon has not been studied on a large scale. Henderson and colleagues test the hypothesis that active learning lowers student evaluations in a population of physics and astronomy instructors who participated in a long-running faculty development workshop. Forty percent (40\%) of new physics and astronomy faculty attended this workshop. Of the more than 1300 workshop participants, 431 responded to a follow-up survey. Participants were asked about their use of active-learning methods in their most recent quantitative physics class; whether their student evaluations were impacted by the use of active learning; and whether students complained about the inclusion of active learning. If a faculty member reported a change in student evaluations, he or she was given an opportunity to provide an explanation for that change.

The majority of respondents saw either an increase $(48 \%)$ or no change in their student evaluations (32\%). The subset of instructors who reported receiving lower teaching evaluations also reported substantially less time lecturing than instructors who reported better evaluations. This pattern seemed driven by people using interactive methods for more than $80 \%$ of a class period, as this population was more likely to report reduced evaluations. Student complaints followed a similar pattern, with an increase in complaints becoming the most common outcome for instructors using active methods more than $80 \%$ of class time.

The reasons shared by instructors for why their evaluations changed were varied. For those who reported their evaluations improving, more than $20 \%$ of the instructors thought this increase was due to each of the following: students believing they were learning more, students enjoying class more, students enjoying interacting with one another, or students enjoying using technology. For those who reported lower evaluations, $40 \%$ reported that the students felt that the instructor was not teaching. Interestingly, many of these instructors also confessed as part of this comment that they were not good at "selling" the active learning. They next most common explanation given for lower evaluations was that students did not like working during class time; they would rather be listeners.
CBE Life Sci Educ March 1, 2019 18:fe1 DOI:10.1187/cbe.18-12-0250

This feature is designed to point CBE-Life Sciences Education readers to current or noteworthy articles for life science educators and education researchers. We invite readers to suggest current themes or articles of interest in life science education as well as influential papers published in the more distant past or in the broader field of education research to be featured in Current Insights. Please send any suggestions to Julia.Gouvea@tufts.edu.

*Address correspondence to: Sarah L. Eddy (seddy@fiu.edu).

(c) 2019 S. L. Eddy. CBE-Life Sciences Education (C) 2019 The American Society for Cell Biology This article is distributed by The American Society for Cell Biology under license from the author(s). It is available to the public under an AttributionNoncommercial-Share Alike 3.0 Unported Creative Commons License (http://creativecommons.org/ licenses/by-nc-sa/3.0).

"ASCB®" and "The American Society for Cell Biology®" are registered trademarks of The American Society for Cell Biology. 
The results of this study suggest that, for the majority of faculty, adopting active learning will not negatively impact student evaluations. The study also suggests that those instructors concerned about student evaluations could incorporate active-learning activities for as much as $80 \%$ of class time and still not be likely to see a negative impact on their evaluations. This could be useful information to share with departmental colleagues and anyone mentoring new faculty who are deciding how to teach. As always, though, some caution should be taken in applying these results in a new context. Specifically, the authors acknowledge that they did not account for what types of active learning instructors implemented. It may be that some methods are more accepted by students than others.

\section{TEACHERS TALKING METACOGNITION}

Zepeda, C. D., Hlutkowsky, C. O., Partika, A. C., \& NokesMalach, T. J. (2018, October 29). Identifying teachers' supports of metacognition through classroom talk and its relation to growth in conceptual learning. Journal of Educational Psychology (advance online publication). https:// doi.org/10.1037/edu0000300

Metacognition refers to one's knowledge and awareness of one's own thought processes. As reviewed in the Introduction, metacognition is considered highly desirable for students, because it has been linked to many positive outcomes in experimental and classroom studies, including achievement, transfer of knowledge from one context to another, and motivation. Although many studies have focused on the use of planned interventions for metacognition, few have looked at what teachers are saying and doing spontaneously in the classroom that might influence student metacognition.

Zepeda and colleagues developed an observation protocol to detect classroom talk directed toward metacognitive growth in middle school students in math classrooms. They identified both the metacognitive content of the talk and the delivery method by documenting four dimensions, each with three possible states: the type of metacognitive knowledge being promoted; the metacognitive skill being worked on; the manner in which the teacher delivered this content; and how specific the metacognitive skill is framed (from specific to the question being worked on to a more global approach to problem solving). For example, a teacher might say, "Alright, so explain to us what you are doing right now." This would be coded as personal knowledge, because the student is asked about his or her own process. The skill being worked on would be monitoring, (i.e., being aware of why they are doing what they are doing). The manner in which the teacher delivers the content would be directive, because the teacher is telling the student to do something. The framing could be domain general, because the prompt could be used with any type of problem. I am not going to go further into the individual states for each dimension due to space, but there are lengthy descriptions of them within the original paper.

The authors use this observation tool with one class session from 39 middle school math instructors. The classes were selected from a larger national data set of middle school classrooms. Every class included in this larger data set had math knowledge assessments. The current authors created a smaller data set that included instructors who had the most student growth on the math assessment over a year and a set of instructors who had the least growth after accounting for various student- and instructor-level factors. Each video was transcribed and each teacher statement was examined for metacognitive talk. Any instance of metacognitive talk was coded for the four dimensions in the observation tool.

Overall, there were very few metacognitive statements made by teachers $(\sim 7 \%$ of teacher statements), but even with this low overall percentage, there were some interesting patterns. The odds of teachers engaging in metacognitive talk were 4.75 times greater during whole-class activities than during activities done individually by students. In addition, in high math growth classes, the odds of instructors engaging in metacognitive talk were 1.5 times higher than in low math growth classes.

The content of the metacognitive talk differed between these two class types as well. In terms of the knowledge dimension, teachers in the high math growth classes elicited more personal knowledge statements in which students shared their own understanding of what they were doing in class than teachers in the low math growth classes. The high math growth class also had more statements focused on the skills of monitoring and evaluating their own work. In terms of how the metacognitive content was delivered (manner), the high math growth class had more directive statements. Finally, the high math growth classes had more domain-general framing of the metacognitive statements.

This study demonstrates that classroom observations can be used to explore metacognition and that the same methods that work most effectively in interventions designed to promote metacognition may also work more informally during teach talk in class. Although the authors cannot rule out that teachers who are more effective in other ways are also more likely to engage in metacognitive talk, the results do suggest that certain ways and certain content of metacognitive talk is more effective than others.

\section{BUILDING STUDENT'S SCIENTIFIC REASONING IN CONVERSATIONS}

Grinath, A. S., \& Southerland, S. A. (2018). Applying the ambitious science teaching framework in undergraduate biology: Responsive talk moves that support explanatory rigor. Science Education, 103(1), 92-122. https://doi .org/10.1002/sce.21484

Active learning is centered around the idea that it encourages students to engage in their own learning, often through conversations about course content. Yet the quality of these conversations can vary. In this paper, Grinath and Southerland explore how instructors can influence in-class student discussions.

To explore the question of facilitation effects without confounding variables of differences between lessons, content, and students, the authors chose to work with 26 teaching assistants (TAs) instructing sections of the same introductory biology lab for nonmajors at the same university. This controlled both the content being presented to students across instructors and the structure of the lessons, as each TA was provided the same slides and the same training in how to conduct the lab. The laboratory lessons were designed around the Ambitious Science Teaching framework described in the Introduction, which is meant to help students engage in the meaningful practices of their discipline, including scientific dialogue. One aspect of this 
framework is helping students connect their everyday explanations of their experiences to the scientific principles underlying them, that is, bridging their everyday way of talking and science talk. This initial conversation is thought to help them meaningfully engage in the subsequent lesson. This study focuses on these initial conversations.

Grinath and Southerland recorded the 8- to 22-minute-long class discussions that opened a lab class exploring how organisms respond to stimuli. At the start of class, students were asked to describe how they experience stress and explain what is driving this response. The authors transcribed the recordings and characterized each TA discourse "move," a statement made by a TA that served a specific communication function. These moves were coded as conservative or ambitious. Conservative patterns follow the traditional classroom pattern, in which the expertise lies with the instructor only. These moves include the instructor asking questions that only have one correct answer, usually about recalling facts or procedures; evaluating a student response as right or wrong; and explaining the connection between the student response and the scientific concept rather than having students make the connection. Ambitious patterns of discourse allow students to be experts, and the instructor is the facilitator. These instructor moves include asking questions with many possible reasonable answers, probing student responses, and pressing students to supply explanations for their answers. Finally, observers also coded TA moves as inclusive or not inclusive. Inclusive moves could include providing opportunities for multiple students to respond to a question, acknowledging a contribution without indicating correctness, and repeating student responses out loud.

The discourse moves were correlated with student talk. Grinath and Southerland used a framework for explanatory rigor of scientific talk to code student responses in the initial class discussion. There were three codes for student answers: fact, observation, and explanation. A turn of student talk was coded as fact if it was short and a vocabulary word or scientific definition not grounded in personal experience. Observations were what a student thought was happening based on personal experience. Finally, explanations were students' ideas of why something was happening. The goal of ambitious science teaching is to help students start making their own explanations of phenomena grounded in science and their own experiences. Thus, TA discourse moves that promoted student explanations were considered the most important in this study.

Using linear regressions with a Bonferroni correction for multiple comparisons, Grinath and Southerland found that conservative discourse moves by TAs were related to an increase in student responses being simply fact statements. Ambitious questions (with multiple possible answers) did not predict student responses, but ambitious responses in which TAs deliberately probed student response and pressed students to expand on their answers did relate to increased explanations. Finally, inclusive moves together related to increased observations given by students.

This work highlights several interesting principles that could be expanded beyond labs. First, it seems that, without deliberately pressing for it (and removing the instructor's explanations), students are not making explanations themselves. They offer facts or observations and wait for the instructor to put them together. Yet explaining phenomena is a key scientific practice and one students should develop. Second, how instructors respond to student answers is critical for creating meaningful conversations in the classroom, maybe even more critical than the qualities of the initial question itself. 